\title{
Osler's nodes, Janeway lesions and splinter haemorrhages
}

\author{
Taishi Hirai, Matthew Koster
}

Department of Internal Medicine, Loyola University Medical Center, Maywood Illinois, USA

\section{Correspondence to} Taishi Hirai, taishi.hirai@gmail.com
To cite: Hirai T, Koster M. BMJ Case Rep Published online: [please include Day Month Year] doi:10.1136/ bcr-2013-009759

\section{DESCRIPTION}

A 22-year-old man with a history of intravenous heroin misuse, presented with 1 week of fatigue and fever. Blood cultures were positive for methicillin-sensitive Staphylococcus aureus. Physical examination showed multiple painful 1$2 \mathrm{~mm}$ macular rashes on the palm and soles bilaterally (figures 1 and 2). Splinter haemorrhages (figure 3) and conjunctival petechiae (figure 4) were also noted. A transoesophageal echocardiogram demonstrated a $16-\mathrm{mm}$ vegetation on the mitral valve (figure 5). Vegitations $>10 \mathrm{~mm}$ in diameter and infection involving the mitral valve are independently associated with an increased risk of embolisation. However, he decided medical management after extensive discussion and was treated with intravenous nafcillin for 6 weeks. He returned 8 weeks later with acute shortness of breath and evidence of a perforated mitral valve for which he subsequently underwent a successful mitral valve repair with an uneventful recovery.

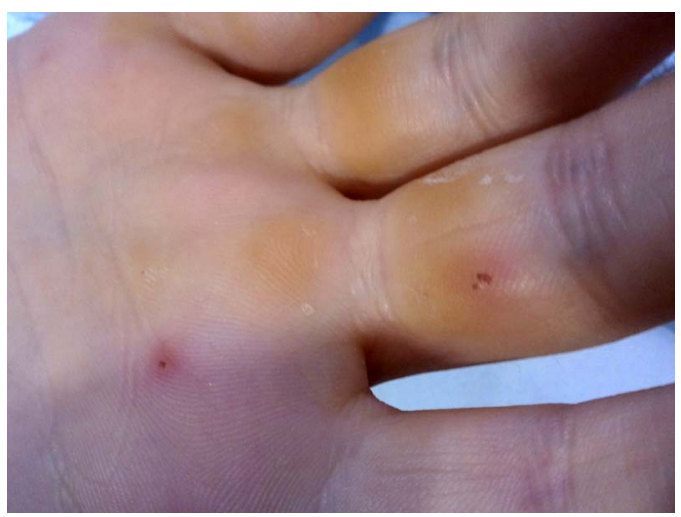

Figure 1 Osler's nodes in the palm and finger.

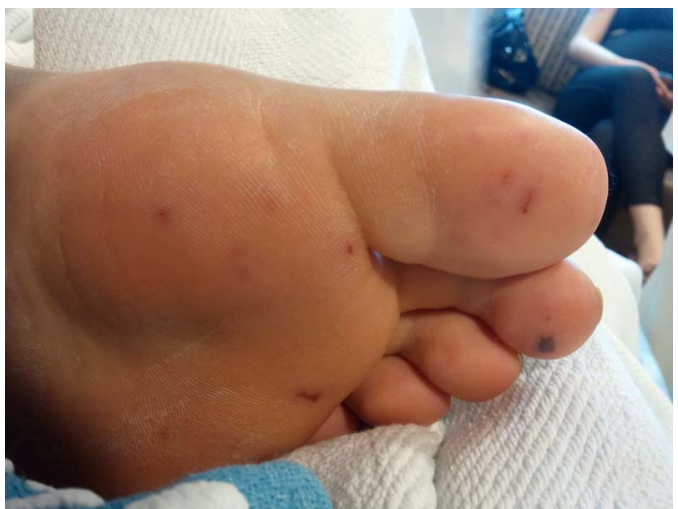

Figure 2 Janeway lesions.

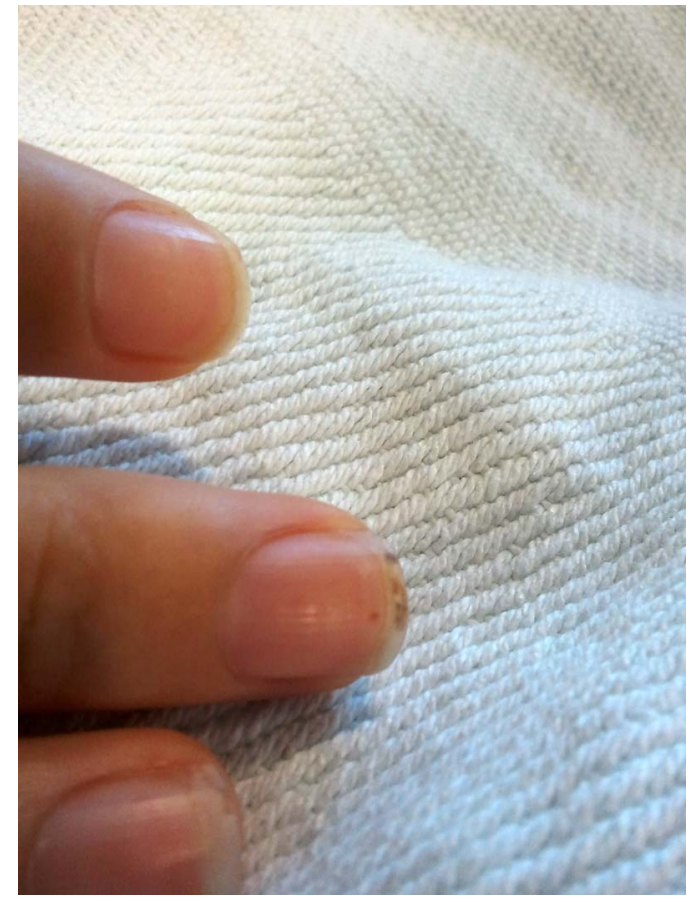

Figure 3 Splinter haemorrhage.

Classically, Osler's nodes are on the tip of the finger or toes and painful. Janeway lesions occur on palm and soles and are non-painful. Osler's nodes are thought to be caused by localised immunological-mediated response while Janeway lesions are thought to be caused by septic microemboli. These findings frequently overlap and are difficult to differentiate. ${ }^{1}$ These appeared in $40-90 \%$ cases of infective endocarditis in preantibiotic era, ${ }^{2}$ however, recent prospective data report the incidence to be $3-5 \% .^{3}$

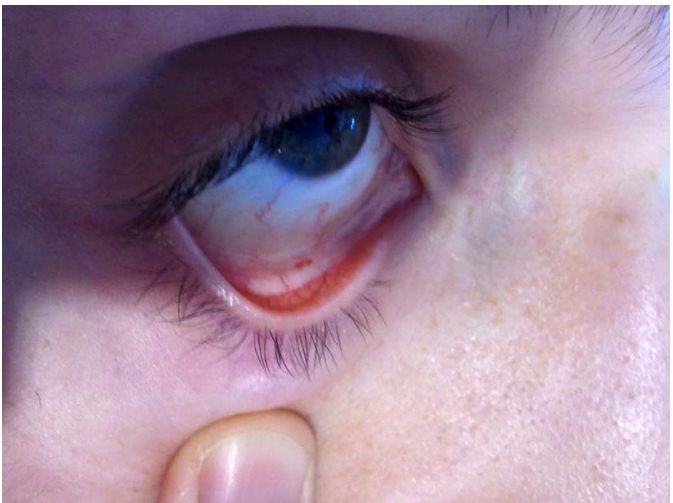

Figure 4 Petechiae in the conjunctiva. 


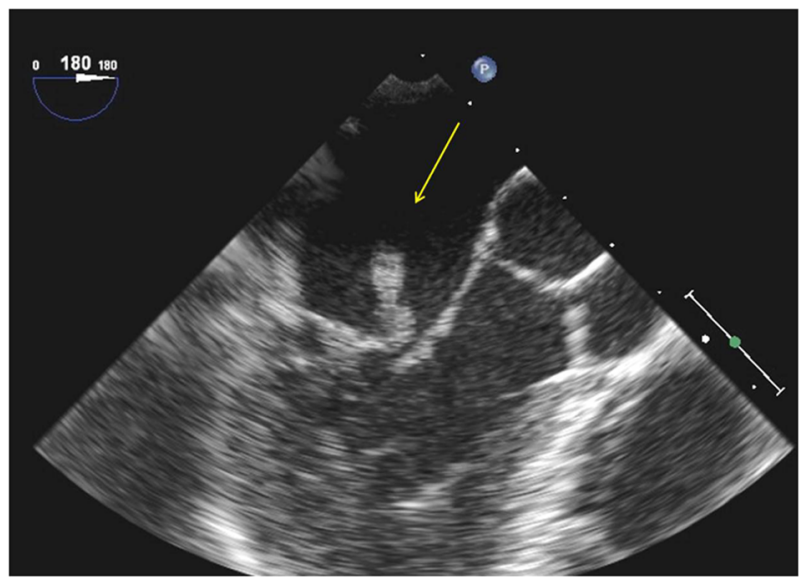

Figure 5 A $16 \times 3 \mathrm{~mm}$ mobile vegetation attached to the posterior leaflet of the mitral valve (arrow) seen by transthoracic echocardiogram.

Splinter haemorrhages are usually oriented in the distal third of the nail. Other causes of splinter haemorrhages include, minor trauma, atrial myxoma and rheumatoid arthritis.

The appearance of Osler's nodes, Janeway lesions and splinter haemorrhages is often coincident with systemic embolisation. It is important to recognise these classic physical findings of infective endocarditis, a condition with high morbidity and mortality in which early diagnosis is the key.

\section{Learning points}

- Janeway lesions and Osler's nodes are found in 3-5\% of cases of infective endocarditis.

- Osler's nodes, Janeway lesions and splinter haemorrhages is often coincident with systemic embolisation.

- It is important for clinicians to recognise these physical findings.

Competing interests None.

Patient consent Obtained.

Provenance and peer review Not commissioned; externally peer reviewed.

\section{REFERENCES}

1 Marrie TJ. Osler's nodes and Janeway lesions. Am J Med 2008;121:105-6.

2 Yee J, McAllister CK. Osler's nodes and the recognition of infective endocarditis: a lesion of diagnostic importance. South Med J 1987;80:753-7.

3 Murdoch DR, Corey GR, Hoen B, et al. Clinical presentation, etiology, and outcome of infective endocarditis in the 21st century: the International Collaboration on Endocarditis-Prospective Cohort Study. Arch Intern Med 2009;169:463-73.

Copyright 2013 BMJ Publishing Group. All rights reserved. For permission to reuse any of this content visit

http://group.bmj.com/group/rights-licensing/permissions.

BMJ Case Report Fellows may re-use this article for personal use and teaching without any further permission.

Become a Fellow of BMJ Case Reports today and you can:

- Submit as many cases as you like

- Enjoy fast sympathetic peer review and rapid publication of accepted articles

- Access all the published articles

- Re-use any of the published material for personal use and teaching without further permission

For information on Institutional Fellowships contact consortiasales@bmjgroup.com

Visit casereports.bmj.com for more articles like this and to become a Fellow 